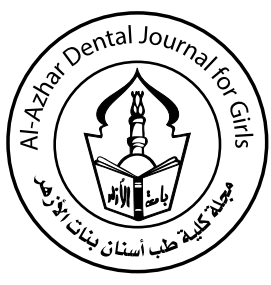

\title{
The Effect of using Cross-Linking Agent with Nano-Adhesive on the Bonding to Sound and Caries Affected Dentin
}

\author{
Mohamed A. Abdelaal ${ }^{(1)}$, Maha A. Niazy ${ }^{(2)}$, Randa M. Hafez ${ }^{(3)}$ and Asmaa A. Yassen ${ }^{(4)}$
}

Codex : 01/1610

dentaljournal.forgirls@yahoo.com

\section{KEYWORDS}

Cross linking agent;

Nanoadhesive;

Microtensile bond strength;

Grape seed extract.

\begin{abstract}
Aim: This study was designed to evaluate the microtensile bond strength and the effect of storage on using two different concentrations $(6.5 \%$ and $15 \%)$ of grape seed extract cross-linking agent with nano-adhesive single bond universal adhesive to sound and caries affected dentin. Methods: A total of sixty molars was divided into 2 main groups (30 each) according to the type of substrate either sound or caries affected dentin. Each group was divided into three equal subgroups (10 teeth each) according to the treatment with cross linking agent (Grape seed extract (GSE)), either with no treatment with GSE or $6.5 \%$ or $15 \%$ GSE dissolved in ethyl alcohol anhydrous. Each subgroup was further subdivided into 2 equal subgroups according to the storage period ( 5 teeth each) either after 24 hours or after 3 months. Resin composite core was built up and then specimens were sectioned to obtain composite-dentin slabs with a cross-sectional area of approximately $1 \mathrm{~mm}^{2}$. They were subjected to microtensile bond strength testing at a cross head speed of $1.0 \mathrm{~mm} / \mathrm{min}$. Statistical analysis was done using three way-ANOVA followed by post hoc test for comparison $(\mathrm{P} \leq 0.05)$. Results: The highest microtensile bond strength mean value was recorded for sound dentin and caries affected dentin, specimens treated with $6.5 \%$ grape seed extract after 24 hours and 3 months storage period, followed by specimens treated with $15 \%$ grape seed extract, while specimens without grape seed extract treatment showed the lowest significant microtensile bond strength mean value. Conclusions: using cross linking agent is considered a beneficial way in improving bonding to sound and caries affected dentin.6.5\%concentration of grape seed extract as a cross linking agent is the concentration of choice to be used. Time has a deteriorating effect on the formed resin -dentin bond.
\end{abstract}

1. Lecturer of Operative Dentistry, Faculty of Oral and Dental Medicine, Nahda University

2. Professor and head of Operative Dentistry Department, Faculty of Dental Medicine Al-Azhar University, Girls Branch

3. Professor of Operative Dentistry, Faculty of Oral and Dental Medicine, Cairo University

4. Associate Professor of Operative Dentistry, Faculty of Oral and Dental Medicine, Cairo University 


\section{INTRODUCTION}

Resin composite restoration lasts in an average of 7 years in posterior teeth. Interfacial failure is considered the primary reason given for resin composite failure. Long term studies revealed that bonding to dentin deteriorated more readily than that to enamel (De Munck et al., 2003; Loguercio et al., 2008). The integrity of fibrillar type I collagen is an important issue for dentin bonding since it is the main component involved during bonding procedures. The hydrolytic and enzymatic breakdown of interfacial collagen is believed to be the leading reason for such degradation. Indeed, exposure of demineralized collagen within the adhesive-resin hybrid layer to the collagenolytic environment is due to many causes such as high water sorption, poor infiltration, and incomplete polymerization of adhesive resins (Wang and Spencer, 2002; Van Meerbeek et al., 2005; Malacarne et al., 2006). Furthermore, matrix metalloproteinases (MMPs), the endogenous collagenases/gelatinases, are activated by the acid-etching process (Breschi et al., 2010).

Consequently, measures that enhance dentin collagen's resistance toward collagenolytic activities have great potential to improve the longevity of dentin bonding. Such a goal of stabilizing collagenous tissues can be achieved by using crosslinking agents (Khor 1997). However, the clinical settings of dental restoration put a constraint on using the cross-linker as it must be effective within a short treatment time. Grape seed extract (GSE) which is rich in proanthocyanidin (PA) seems to be highly promising as a cross linking agent incorporated in the dentin bonding agent. Earlier studies have established that GSE-PA is an efficient collagen cross-linker taking moderate to long treatment times (Bedran-Russo et al., 2007; Castellan et al., 2010; Green et al., 2010; Liu et al., 2011). Its extraordinary cross-linking efficacy within very short treatment times ( $<30$ second) was discovered recently (Liu et al., 2013a; Liu et al., 2013b). Moreover, GSE-PA exhibits superior inhibitory effect (compared with chlorhexidine) on such endogenous enzymes as MMP-2, MMP-8, and MMP9 (Epasinghe et al., 2013). Furthermore, the low toxicity of GSE-PA supports its use in intraoral applications (Yamakoshi et al., 2002). Nonetheless, incorporation of GSE in self-etch adhesives is limited because PA readily scavenges free radicals in the adhesive (Quideau et al., 2011) and consequently hampers the polymerization of adhesive resins (Liu and Wang 2013).

Studies have used sound dentin as the bonding substrate (Armstrong et al., 2003; De Munck et al., 2003). However, in clinical settings, the substrate being bonded often involves caries-affected dentin, in which the bond strength is lower than that of sound dentin (Nakajima et al., 1995; Yoshiyama et al., 2002; Ceballos et al., 2003). Therefore, potential improvement in the quality of the tooth-restoration complex should consider the effectiveness of different dentin treatments on sound and cariesaffected dentin.

Recently, nanoparticles have been used in the formulation of restorative composite systems (Mitra et al., 2003). With the aim of improving physical and mechanical properties, nanoparticles have also been incorporated into the dental adhesives. Because of their very small sizes, nanoparticles are able to penetrate into the dentinal tubules along with the adhesive resin matrix providing a composite adhesive layer with improved properties (decreased polymerization shrinkage and increased the elastic modulus of the adhesive layer) (Kim et al., 2005 ; Atai et al., 2009).

\section{MATERIALS AND METHODS}

\section{Teeth preparation}

A total of sixty molars was extracted and collected, thirty sound impacted human third molars to obtain specimens of sound dentin and another thirty human molars with simple non cavitated oclussal caries to obtain specimens of caries affected dentin. 


\section{Dentin surface pre-treatment}

The flat surfaces were acid-etched for $15 \mathrm{sec}-$ onds with $37 \%$ phosphoric acid, then the teeth were divided into 2 main groups (30 teeth each) according to the type of substrate either sound or caries affected dentin. Each group was divided into three equal subgroups (10 teeth each) according to the dentin treatment with cross linking agent (Grape seed extract(GSE)). In the first subgroup no treatment with GSE (control), in the second subgroup $6.5 \%$ GSE dissolved in ethyl alcohol anhydrous was used, and in the third subgroup 15\% GSE dissolved in ethyl alcohol anhydrous was used. Each subgroup was further subdivided into 2 equal classes (5 teeth each) according to the storage period either 24 hours or 3 months.

The GSE solution was applied once and left for a minute to be gently rinsed thoroughly with water and dried. Two layers of the Nanofilled single bond universal adhesive were applied then composite resin core was built up and then specimens were sectioned to obtain composite-dentin slabs with a cross-sectional area of approximately $1 \mathrm{~mm}^{2}$ slabs(Figure 1) according to the technique for the non trimming version of the micro- tensile bond strength test reported by Sano et al. in 1994 .

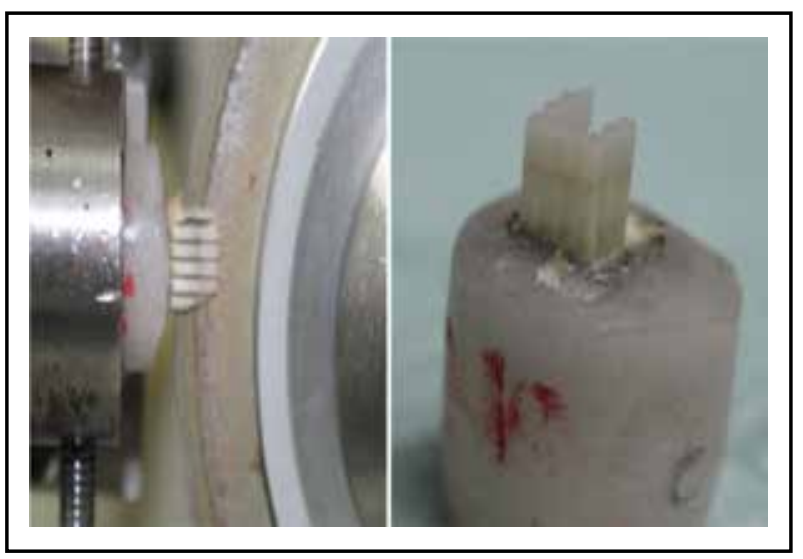

Fig. (1) Sectioning the tooth in the bucco-lingual and mesiodistal direction using hard tissue microtome.

One hundred and twenty slabs were taken from 60 human molar (2 slabs/ 1 tooth). Finally each specimen was attached to instron testing machine with a cyanoacrylate adhesive and stressed by tensile forces at a cross head speed of $1 \mathrm{~mm} /$ minute until failure occurs (Figure 2). Calculation of the bond strength was done by dividing the magnitude of the applied force by the cross sectional area of the specimens and expressed in MPa. Immediately after microtensile bond strength test the fractured side of all specimens was examined using a digital microscopic at $50 \times$ magnification and photographed using image analysis software to determine the mode of fracture . either adhesive, cohesive in dentin, or cohesive in composite or mixed (Calvacante et al,.2006). Data were collected, recorded, tabulated and statistically analyzed.

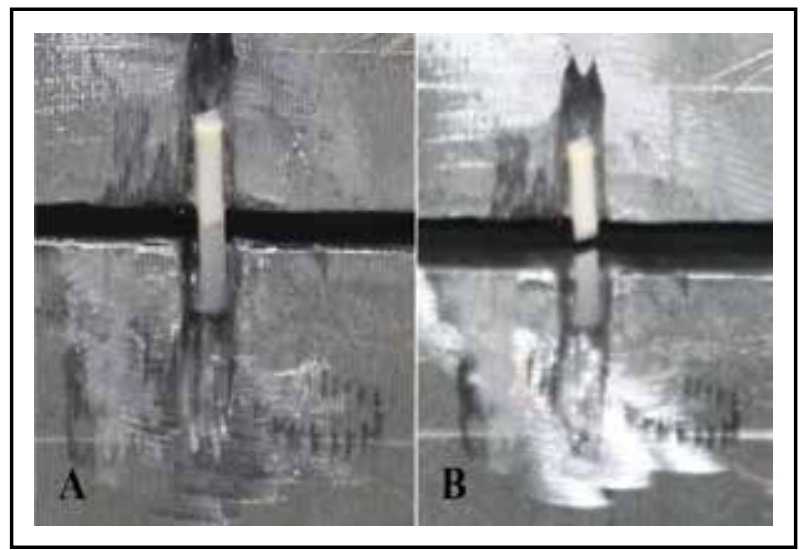

Fig. (2) A- Dentin composite slab specimen glued to the jig before force application.

B- Fractured dentin composite slab specimen fixed in the attachment jig after force application.

\section{RESULTS}

\section{a. Effect of cross-linking agent concentration on mean micro-tensile bond strength (MPa) within each substrate and storage period:}

Table (1) and figure (3) revealed mean, standard deviation (SD) and statistical significance for the micro-tensile bond strength (MPa) for cross-linking agent concentration within each substrate and storage period. They showed that the microtensile bond strength value after 24 hours storage period of sound dentin specimens treated with $6.5 \%$ grape seed extract showed the highest statistically 
significant microtensile bond strength mean value $36.57( \pm 8.58) \mathrm{MPa}$ followed by specimens treated with $15 \%$ grape seed extract $34.11( \pm 8.81) \mathrm{MPa}$ while specimens without grape seed extract treatment showed the lowest significant mean microtensile bond strength mean value 24.53( \pm 5.7$) \mathrm{MPa}$. The difference in microtensile bond strength mean values between all the treated groups was statistically significant at $\mathrm{p}=0.005$. The difference between difference between 6.5\%GSE and 15\% GSE was statistically non significant.

The microtensile bond strength value after 3 months storage period of sound dentin specimens treated with $6.5 \%$ grape seed extract showed the highest statistically significant microtensile bond strength mean value $29.85( \pm 7.84) \mathrm{MPa}$ followed by specimens treated with $15 \%$ grape seed extract 27.93( \pm 9.57$) \mathrm{MPa}$ while specimens without grape seed extract treatment showed the lowest significant mean microtensile bond strength mean value 18.48( \pm 4.22$) \mathrm{MPa}$. The difference in microtensile bond strength mean values between all the treated groups was statistically significant at $\mathrm{p}=0.005$.The difference between difference between 6.5\%GSE and $15 \%$ GSE was statistically non significant.

The microtensile bond strength value after 24 hours storage period of caries affected dentin specimens treated with $6.5 \%$ grape seed extract showed the highest statistically significant microtensile bond strength mean value 35.97( \pm 7.57$)$ MPa followed by specimens treated with $15 \%$ grape seed extract $33( \pm 9.23) \mathrm{MPa}$ while specimens without grape seed extract treatment showed the lowest significant mean microtensile bond strength mean value 22.03( \pm 8.15$) \mathrm{MPa}$. The difference in microtensile bond strength mean values between all the treated groups was statistically significant at $\mathrm{p}=0.002$. The difference between difference between $6.5 \% \mathrm{GSE}$ and $15 \%$ GSE was statistically non significant.

The microtensile bond strength value after 3 months storage period of caries affected dentin specimens treated with $6.5 \%$ grape seed extract showed the highest statistically non significant microtensile bond strength mean value 26.02 $( \pm 9.32) \mathrm{MPa}$ followed by specimens treated with $15 \%$ grape seed extract 22.31( \pm 6.48$) \mathrm{MPa}$ while specimens without grape seed extract treatment showed the lowest non significant mean microtensile bond strength mean value 20.61 $( \pm 4.99) \mathrm{MPa}$. The difference in microtensile bond strength mean values between all the treated groups was statistically non significant at $\mathrm{P}=0.243$.

Table (1) Mean, standard deviation (SD) and statistical significance of microtensile bond strength (MPa) for cross-linking agent concentrations within each substrate and storage period.

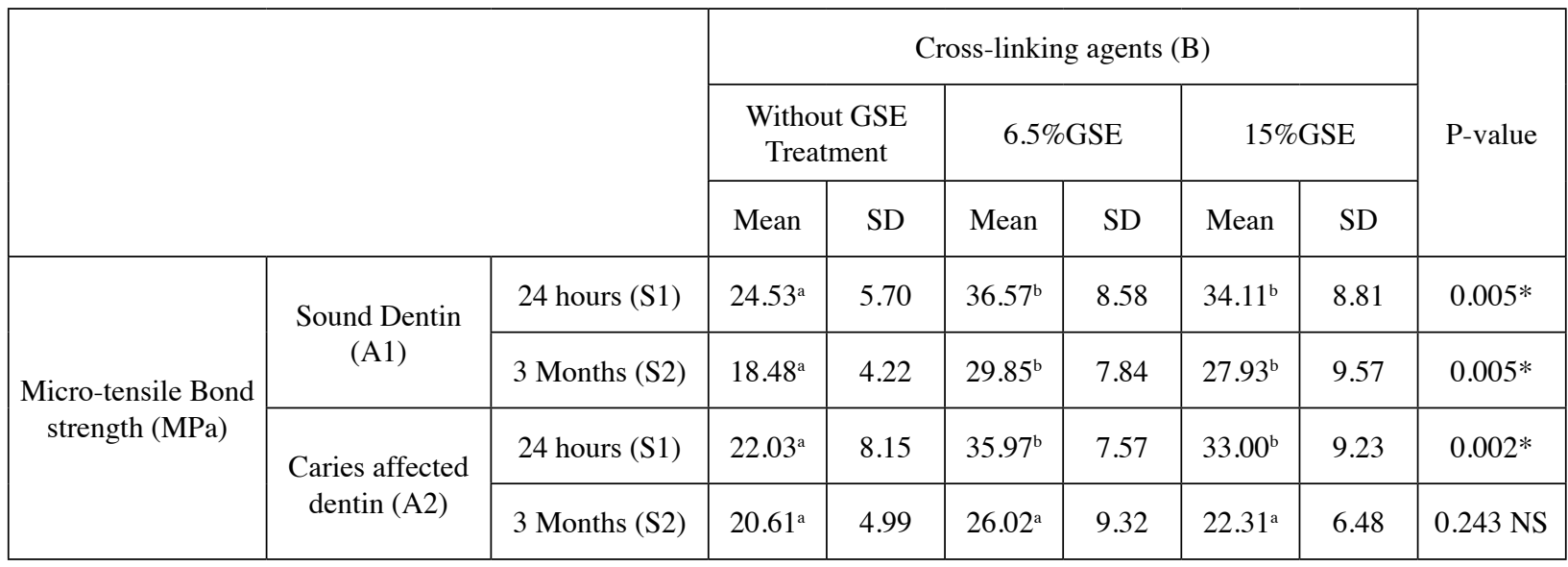

Means with the same letter within each row are not significantly different. $\quad *=$ Significant, NS=Non-significant. 


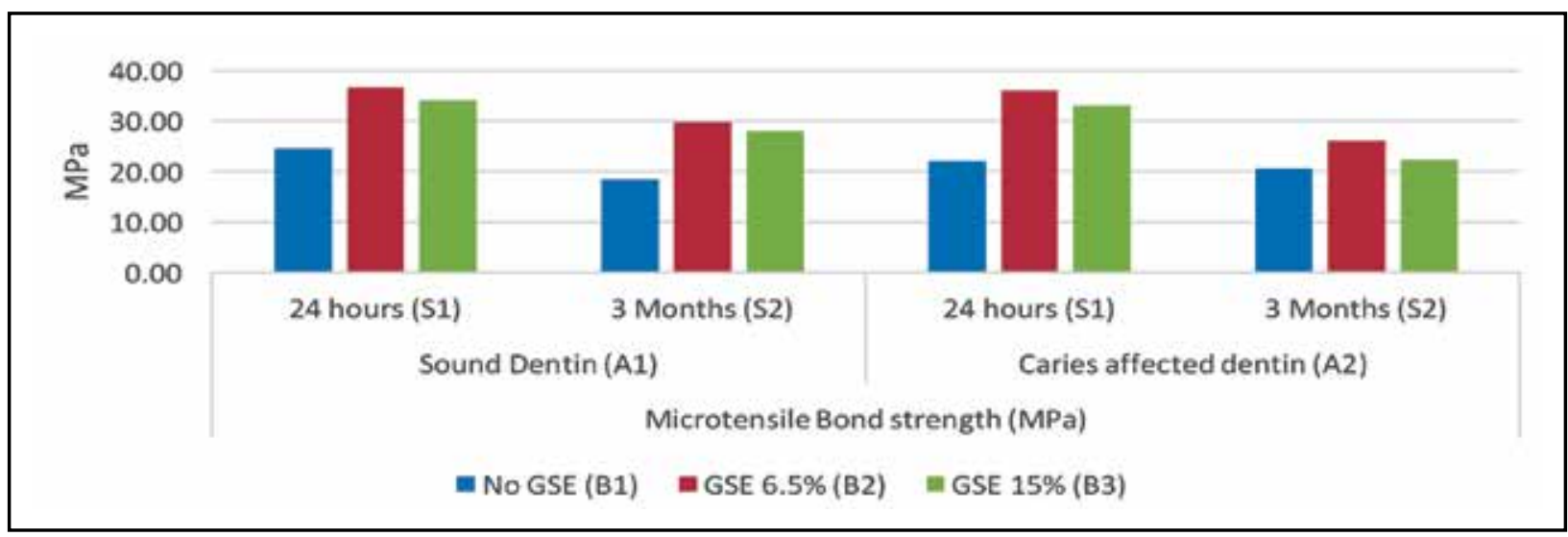

Fig. (3) Histogram showing the mean microtensile bond strength (MPa) for cross-linking agent concentrations within each substrate and storage period.

b. Effect of different cross-linking agent concentration on mode of failure within each substrate and storage period:

Table (2) and figure (2) revealed percentage of mode of failure and statistical significance for crosslinking agent concentration within each substrate and storage period. The results revealed that sound dentin specimens without grape seed extract treatment after 24 hours and 3 months storage period have higher percentage in adhesive failure. Sound dentin specimens treated with $6.5 \%$ grape seed extract after 24 hours and 3 months storage period have higher percentage in mixed failure. Sound dentin specimens treated with $15 \%$ grape seed ex- tract after 24 hours storage period have higher percentage in mixed failure, while after 3 months it has higher percentage in adhesive failure. Caries affected dentin specimens without grape seed extract treatment after 24 hours and 3 months storage period have higher percentage in adhesive failure.

Caries affected dentin specimens treated with $6.5 \%$ grape seed extract after 24 hours storage period have higher percentage in mixed failure while after 3 months it has higher percentage in adhesive failure. Caries affected dentin specimens treated with $15 \%$ grape seed extract after 24 hours and 3 months storage period have higher percentage in adhesive failure.

Table (2) Percentage of mode of failure and statistical significance for cross-linking agent concentration within each substrate and storage period.

\begin{tabular}{|c|c|c|c|c|c|c|c|c|c|c|}
\hline & & \multicolumn{8}{|c|}{ Substrate (A) } & \multirow{4}{*}{$\mathrm{P}$-value } \\
\hline & & \multicolumn{3}{|c|}{ Sound Dentin (A1) } & \multicolumn{4}{|c|}{ Caries affected dentin (A2) } & \multirow[b]{2}{*}{$\begin{array}{c}\text { Cohesive in } \\
\text { composite }\end{array}$} & \\
\hline & & Adhe-sive & Mixed & $\begin{array}{l}\text { Cohesive } \\
\text { in dentin }\end{array}$ & $\begin{array}{l}\text { Cohesive in } \\
\text { composite }\end{array}$ & Adhesive & Mixed & $\begin{array}{l}\text { Cohesive } \\
\text { in dentin }\end{array}$ & & \\
\hline & & $\%$ & $\%$ & $\%$ & $\%$ & $\%$ & $\%$ & $\%$ & $\%$ & \\
\hline \multirow{2}{*}{$\begin{array}{l}\text { Without } \\
\text { GSE }\end{array}$} & 24 hours (S1) & $60.0 \%$ & $20.0 \%$ & $10.0 \%$ & $10.0 \%$ & $70.0 \%$ & $0.0 \%$ & $10.0 \%$ & $20.0 \%$ & $0.912 \mathrm{NS}$ \\
\hline & 3 Months (S2) & $40.0 \%$ & $30.0 \%$ & $10.0 \%$ & $20.0 \%$ & $50.0 \%$ & $40.0 \%$ & $0.0 \%$ & $10.0 \%$ & $0.529 \mathrm{NS}$ \\
\hline \multirow{2}{*}{$6.5 \% \mathrm{GSE}$} & 24 hours (S1) & $10.0 \%$ & $70.0 \%$ & $20.0 \%$ & $0.0 \%$ & $30.0 \%$ & $60.0 \%$ & $10.0 \%$ & $0.0 \%$ & $0.353 \mathrm{NS}$ \\
\hline & 3 Months (S2) & $30.0 \%$ & $40.0 \%$ & $20.0 \%$ & $10.0 \%$ & $40.0 \%$ & $30.0 \%$ & $30.0 \%$ & $0.0 \%$ & $0.739 \mathrm{NS}$ \\
\hline \multirow{2}{*}{$15 \% \mathrm{GSE}$} & 24 hours (S1) & $30.0 \%$ & $60.0 \%$ & $0.0 \%$ & $10.0 \%$ & $60.0 \%$ & $20.0 \%$ & $10.0 \%$ & $10.0 \%$ & $0.436 \mathrm{NS}$ \\
\hline & 3 Months (S2) & $40.0 \%$ & $30.0 \%$ & $10.0 \%$ & $20.0 \%$ & $70.0 \%$ & $10.0 \%$ & $10.0 \%$ & $10.0 \%$ & $0.315 \mathrm{NS}$ \\
\hline
\end{tabular}

Statistically significantly different at $P \leq 0.05 . \quad *=$ Significant, NS=Non-significant. 


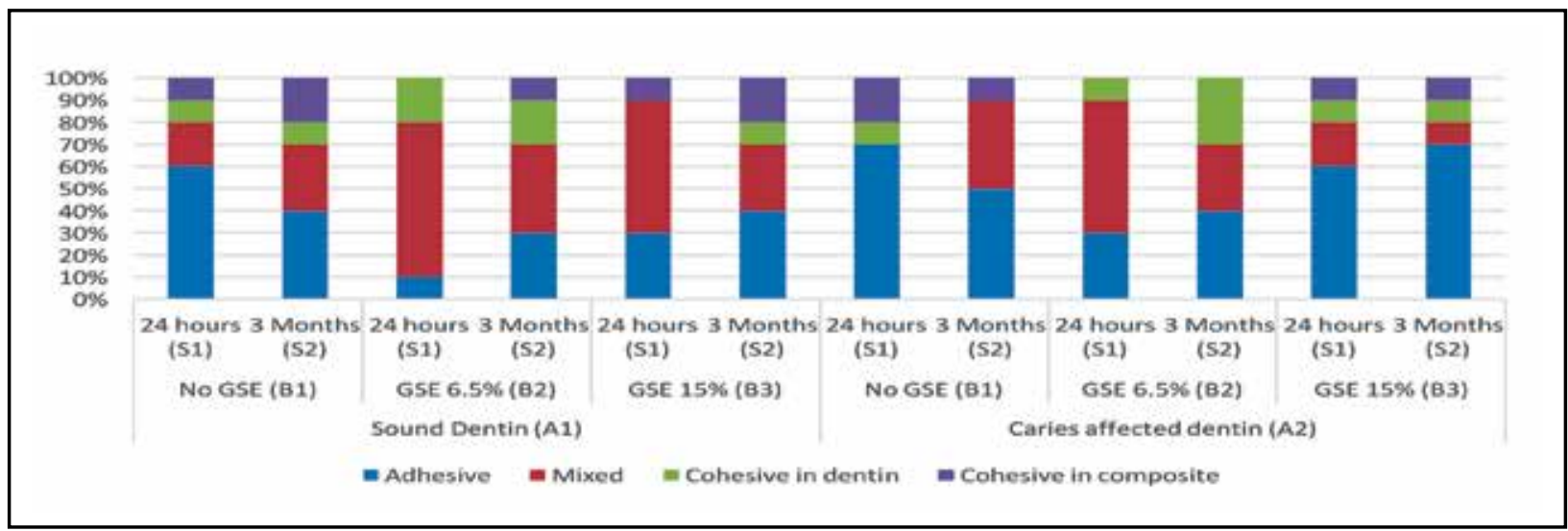

Fig. (4) Histogram showing the percentage of mode of failure for cross-linking agent concentration within each substrate and storage period.

\section{DISCUSSION}

Grape seed extract is composed mainly of proanthocyanidin, a naturally occurring cross linking agent. It's use on demineralized dentin has been associated with a significant improvement in the mechanical and physical properties of dentin (BedranRusso et al., 2007 and 2008). In details proanthocyanidin or condensed tannins is composed of condensed flavon-3-ol subunits, catechin, epicatechin and epicatechin-3-O-gallate and linked mainly through $\mathrm{C} 4-\mathrm{C} 8$. These components are responsible for their various biological properties such as free-radical scavenging and antioxidant activities. Proanthocyanidin consists of highly-hydroxylated structures that are capable of forming insoluble complexes with carbohydrates and proteins. It has been shown to interact with proline-rich proteins like collagen by covalent linkages, ionic interaction, hydrogen and hydrophobic bonding interactions. Formation of hydrogen bonds between the phenolic hydroxyl and protein amide carbonyl groups are the major force for stabilizing PA-treated collagen and increasing its mechanical properties. Furthermore, the triple helical structure of collagen also facilitates the accessibility of the carbonyl oxygen of the peptide backbone for hydrogen bonding (Epasinghe et al., 2012). The use of grape seed extract treatment in the present study regardless of its concentration increased the microtensile bond strength to sound and caries affected dentin (table1 and figure 3 ).
The increase in mixed mode failure at resin / adhesive interface after being treated with GSE (table 2 and figure 4) may indicate that the hybrid layer was strengthened by cross-linkers. This is in agreement with Macedoo et al., 2009 and Walter et al.,2008 who reported that collagen cross linking induced by PA is more resistant to endogenous collagenase enzyme and provide more durable collagen layer than untreated control group

However, these results contradict those of Islam et al., 2012 who studied the effect of natural crosslinkers incorporation in a self-etching primer on the microtensile dentin bond strength and obtained low bond strength values of GSE treated specimens. They referred their results to the poorly dissolved smear layer and the occlusion of dentinal tubules by smear particles in dentine conditioned with GSEincorporated primer. This adverse effect of GSE on dissolving smear layer is related to the apparent molecular size of GSE. Since GSE contained oligomeric proanthocyanidins, the apparent molecular size might be manifold. The chemical nature with increased molecular size would compromise the penetration and diffusion of functional monomers of the primer. The amount of monomer diffusion into the demineralized dentine and polymerization of diffused monomers account for the quality of the bonding systems. Incomplete infiltration of resin monomer may hamper ideal hybridization of dentine and monomers, leading to low bond strength 
(Islam et al., 2012). However, in the present study the GSE was rinsed after one minute following its application which could have resulted in clearing the surface from the smear particles and other contaminates thereby increasing the penetration and the diffusion of the monomer into the dentin thus enhancing the bond strength. The finding of the present study is also in agreement with Al-Ammar et al., 2009, Green et al., 2010 and Dos Santos et al., 2011 who reported that pre-treatment with GSE when applied on etched dentine prior to bonding with etch-and-rinse adhesive systems improved the bond strength and postulated that the increase in mechanical properties of GSE-treated dentine is the cause of improved bond strength of the etch-andrinse adhesives.

Furthermore, on comparing the microtensile bond strength of sound and caries affected dentin, it was found that there was no statistically difference between them (table 1 and figure 3). This finding is in agreement with Macedo et al., 2009 and Epasinghe et al.,2012. They found that when caries affected dentin was treated with grape seed extract, the bond strength reached values comparable with those of sound dentin, indicative of increasing the collagen stability together with the possibility that as well as the cross-linked dentin matrix might mechanically strengthen the incomplete resin infiltrated demineralized zone at the bottom of the hybrid layer. This was inspite of the finding of the previous studies which found that untreated caries affected dentin exhibited lower bond strength values when compared with sound dentin and this could be attributed to the altered or partially denatured dentin matrix (predominantly type I collagen) (Yoshiyama et al., 2002) and /or the relative paucity of resin tags in mineral filled tubules (Marshall et al.,2001). The change in chemical and morphological characteristics of caries affected dentin would be also reasons for the lower bond strength. The hybrid layers created with the caries-affected dentin are thicker than those of sound dentin, because caries affected dentin is more susceptible to the acid etching due to partially demineralization, resulting in the formation of a deeper demineralized zone (Nakajima et al., 2011).

The fractographic analysis results revealed similar failure modes in both groups of sound and caries affected dentin regardless of the other variables (table 2). This observation correlate with the microtensile bond strength results.

The result of the present study revealed that the microtensile bond strength of sound and caries affected dentin decreased significantly after 3 months storage period. Water sorption by hydrophilic and ionic resin monomers within both the hybrid layer and the adhesive layer may contribute to the degradation of resin -dentin bond strength over time. Moreover, incompletely infiltrated deeper areas in the hybrid layer contain denuded collagen fibrils, which are responsible for degradation and also provide a pathway for host derived enzymes. Theses enzymes are a class of zinc and calcium dependent endopepetides and are responsible for auto-degradation of collagen matrices. This might lead to hydrolytic degradation, increases nanoleakage, and loss of bond strength over time due to thinning and disappearance of collagen fibrils from incompletely infiltrated aged hybrid layer. The activity of MMPs can be suppressed by protease inhibitors.

It has been considered that the use of cross linking agent achieve dentin resin bond longevity through collagen preservation. (Al-Ammar et al.,2009 and Macedo et at al., 2009), found that in vitro application of PA to etched dentin prior to bonding procedures enhanced the immediate dentin bond strength and dentin collagen stability of caries affected and sound dentin. However, in their study, etched dentin surface was treated with $6.5 \%$ grape seed extract for one hour. Such protocol was time consuming and clinically irrelevant.

In the present study one minute application of grape seed extract regardless of its concentration yielded increased immediate bond strength but unfourtuonetly it could not preserve the obtained bond 
strength at 3 months as shown in (table $\mathbf{1}$ and figure 3). This might be attributed to the short time of application of GSE (one minute) and also the rinsing step as mentioned previously.

Contrary to the present study (Verma et al., 2013) found a significant preservation of bond strength after 6 months of water storage. Moreover, (Green et al.,2010) who used adhesives with and without 5\% PA concluded that incorporation of PA in dental adhesives may inhibit the biodegradation of unprotected collagen fibrils (Green et al.,2010). Preservation of bond integrity was referred to the hydrogen bonding between proteins amide carbonyl and the phenolic hydroxyl (Hagerman et al.,1981). Proline-rich proteins like collagen have an extremely high affinity for PA especially at isoelectric pH (Han et al., 2003 and Hagerman et al.,1981). When the collagen molecules are cross linked, some of the sites that serve as substrate for collagenases could be hidden or modified due to protein folding and the enzymatic digestion can also be hindered (Liu et al.,2011). In addition, PA has a good and proven antioxidant effect (Tabatabaei et al., 2011). as well as its potential inhibition of MMP8 and MMP9.

The effect of PA is many fold, stiffening or fixing the collagen thus decreasing susceptibility of the collagen to enzymatic decay, antioxidant properties reducing the oxygen inhibition layer and thus decreasing the osmotic blistering, supplemented by its own antibacterial effect (Castellan et al.,2010 and Tabatabaei et al., 2011). The fact that all these functions were attained while keeping the application time clinically feasible indicates that this technique has a great promise in the future of adhesive dentistry but after some studies to be clinically performed.

\section{CONCLUSION}

1. Using of cross linking agent is considered a beneficial way in improving bonding to sound and caries affected dentin.
2. $6.5 \%$ concentration of grape seed extract as a cross linking agent is the concentration of choice to be used.

3. Time has a deteriorating effect on the formed resin -dentin bond.

\section{REFERENCES}

- Al-Ammar A, Drummond JL and Bedran-Russo AK: The use of collagen cross-linking agents to enhance dentin bond strength. Journal of Biomedical Materials Research part B: Applied Biomaterials,2009 Oct; 91(1): 419-424.

- Armstrong SR, Vargas MA, Fang Q and Laffoon JE : Microtensile bond strength of a total-etch 3-step, totaletch 2-step, self-etch 2-step, and a self-etch 1-step dentin bonding system through 15-month water storage. Journal of Adhesive Dentistry,2003 Spring ;5(1):47-56.

- $\quad$ Atai M, Solhi L, Nodehi A, Mirabedini SM, Kasraei S, Akbari K and Babenzadeh S: PMMA-grafted nanoclay as novel filler for dental adhesives. Dental Materials Journal, 2009 Mar ;25 (3):339-347.

- $\quad$ Bedran-Russo AK, Pashley DH, Agee K, Drummond JL and Miescke $\mathrm{KJ}$ : Changes in stiffness of demineralized dentin following application of collagen crosslinkers. Journal of Biomedical Materials Research part B: Applied Biomaterials,2008 Aug; 86 (2):330-334.

- $\quad$ Bedran-Russo AK, Pereira PN, Duarte WR, Drummond JL and Yamauchi M:Application of crosslinkers to dentin collagen enhances the ultimate tensile strength. Journal of Biomedical Materials Research part B: Applied Biomaterials, 2007 Jan ;80 (1):268-272.

- Breschi L, Martin P, Mazzoni A, Nato F, Carrilho M, Tjäderhane L and et al.: Use of a specific MMP-inhibitor (galardin) for preservation of hybrid layer. Dental Materials Journal, 2010 Jun; 26 (6):571-578.

- $\quad$ Castellan CS, Pereira PN, Grande RH, Bedran-Russo AK : Mechanical characterization of proanthocyanidin-dentin matrix interaction. Dental Materials Journal, 2010 Oct; 26 (10):968-973.

- Cavalcante LM, Erhardt MC, Bedran-de-Castro AK, Pimenta LA and Ambrosano GM: Influence of different tests used to measure the bond strength to dentin of two adhesive systems. American Journal of Dentistry, 2006 Feb;19(1):37-40.

- Ceballos L, Camejo DG, Fuentes VM, Osorio R, Toledano M, Carvalho RM and Pashley DH: Microtensile bond 
strength of total-etch and self etching adhesives to cariesaffected dentine. Journal of Dentistry, 2003 Sep ;31 (7):469-477.

- Dos Santos PH, Karol S and Bedran-Russo AK : Longterm nano-mechanical properties of biomodified dentinresin interface components. Journal of Biomechanics, 2011 Jun;44(9): 1691-1694.

- De Munck J, Van Meerbeek B, Inoue S, Vargas M, Yoshida Y, Armstrong S and et al.: Micro-tensile bond strength of one- and two-step self-etch adhesives to burcut enamel and dentin. American Journal of Dentistry,2003 Dec;16(6):414-420.

- $\quad$ Epasinghe DJ, Yiu CK, Burrow MF, Hiraishi N and Tay FR : The inhibitory effect of proanthocyanidin on soluble and collagen-bound proteases. Journal of Dentistry,2013 Sep; 41(9):832-839.

- $\quad$ Epasinghe DJ, Yiu CK, Burrow MF, Tay FR and King $\mathrm{NM}$ : Effect of proanthocyanidin incorporation into dental adhesive resin on resin-dentine bond strength. Journal of Dentistry,2012 Mar;40(3):173-180.

- Green B, Yao X, Ganguly A, Xu C, Dusevich V, Walker MP and et al. : Grape seed proanthocyanidins increase collagen biodegradation resistance in the dentin/adhesive interface when included in an adhesive. Journal of Dentistry,2010 Nov; 38 (11):908-915.

- Hagerman AE and Butler LG: The specificity of proanthocyanidin-protein interactions. Journal of Biological Chemistry, 1981 May;256 (9) :4494 - 4497.

- Han B, Jaurequi J, Tang BW and Nimni ME : Proanthocyanidin: a natural crosslinking reagent for stabilizing collagen matrices. Journal of Biomedical Materials Research A, 2003 Apr; 65(1): 118-124.

- Islam S, Hiraishi N, Nassar M, Yiu C, Otsuki M and Tagami J: Effect of natural cross-linkers incorporation in a self-etching primer on dentine bond strength. Journal of Dentistry, 2012 Dec;40(12):1052-1059.

- Khor E: Methods for the treatment of collagenous tissues for bioprostheses. Biomaterials Journal,1997 Jan;18 (2):95-105.

- Kim JS, Cho BH, Lee IB, Um CM, Lim BS, Oh MH and et al: Effect of the hydrophilic nanofiller loading on the mechanical properties and the microtensile bond strength of an ethanol-based one-bottle dentin adhesive. Journal of Biomedical Materials Research part B: Applied Biomaterials, 2005 Feb;72B (2):284-291.
- $\quad$ Liu Y, Tjäderhane L, Breschi L, Mazzoni A, Li N, Mao J, Pashely DH and Tay FR: Limitations in bonding to dentin and experimental strategies to prevent bond degradation. Journal of Dental Research, 2011Aug;90(8):953-968.

- $\quad$ Liu Y, Chen M, Yao X, Xu C, Zhang Y and Wang Y (a): Enhancement in dentin collagen's biological stability after proanthocyanidins treatment in clinically relevant time periods. Dental Materials Journal, 2013 Apr; 29(4): 485-492.

- $\quad$ Liu Y, Dusevich V and Wang Y (b): Proanthocyanidins rapidly stabilize the demineralized dentin layer. Journal of Dental Research, 2013 Aug;92(8):746-752.

- $\quad$ Liu Y and Wang Y: Effect of proanthocyanidins and photoinitiators on photo-polymerization of a dental adhesive. Journal of Dentistry,2013 Jan; 41(1):71-79.

- Loguercio AD, Moura SK, Pellizzaro A, Dal-Bianco K, Patzlaff RT, Grande

- $\quad$ RH and et al.: Durability of enamel bonding using twostep self etch systems on ground and unground enamel. Operative Dentistry,2008 Jan ;33(1):79-88.

- Macedo GV, Yamauchi M and Bedran-Russo AK: Effects of chemical cross-linkers on caries-affected dentin bonding. Journal of Dental Research, 2009 Dec;88(12):1096-1100.

- Malacarne J, Carvalho RM, de Goes MF, Svizero N, Pashley DH, Tay FR and et al.: Water sorption/solubility of dental adhesive resins. Dental Materials,2006 Oct; 22 (10):973-980.

- Marshall GW Jr, Chag YJ, Gansky SA and Marshall SJ : Demineralization of caries-affected transparent dentin by citric acid: an atomic force microscopy study. Dental Materials Journal, 2001 Jan; 17(1):45-52.

- Mitra SB, Wu D and Holmes BN: An application of nanotechnology in advanced dental materials. Journal of American Dental Association, 2003 Oct ;134 (10):1382-1390.

- Nakajima M, Kunawarote S, Prasansuttiporn T and Tagami J: Bonding to caries-affected dentin. Japanese Dental Science Review,2011 Aug;47(2):102-114.

- Nakajima M, Sano H, Burrow MF, Tagami J, Yoshiyama M, Ebisu S and et al.: Tensile bond strength and SEM evaluation of caries-affected dentin using dentin adhesives. Journal of Dental Research,1995 Oct; 74 (10):1679-1688.

- Quideau S, Deffieux D, Douat-Casassus C and Pouységu L : Plant polyphenols: chemical properties, biological activities, and synthesis. Angewandte Chemie International Edition in English,2011 Jan; 50 (3):586-621. 
- Sano H, Sonoda H, Shono T, Takatsu T, Ciucchi B, Carvalho R and Pashley D: Relationship between surface area for adhesion and tensile bond strength evaluation of a microtensile bond test. Dental Materials,1994 Jul; 10(4):236-240.

- Tabatabaei MH, Arami S, Nojoumian A, Mirzaei M: Antioxidant effect on the shear bond strength of composite to bleached bovine dentin. Brazilian Journal of Oral Sciences, 2011 Jan-Mar;10(1):33-36.

- Van Meerbeek B, Van Landuyt K, De Munck J, Hashimoto M, Peumans M, Lambrechts $\mathrm{P}$ and et al.: Techniquesensitivity of contemporary adhesives. Dental Materials Journal, 2005 Mar ;24 (1):1-13.

- Verma R, Singh UP, Tyagi SP, Nagpal R, and Manuja $\mathrm{N}$ : Long-term bonding effectiveness of simplified etchand-rinse adhesives to dentin after different surface pretreatments. Journal of Conservative Dentistry,2013 JulAug; 16(4): 367-370.
Walter R, Miguez PA, Arnold RR, Pereira PN, Duarte WR and Yamauchi M: Effects of natural cross-linkers on the stability of dentin collagen and the inhibition of root caries in vitro. Caries Research Journal,2008 Aug ;42(4): 263-268.

- Wang Y and Spencer P: Quantifying adhesive penetration in adhesive/ dentin interface using confocal raman microspectroscopy. Journal of Biomedical Materials Research,2002 Jan ;59(1):46-55.

- Yamakoshi J, Saito M, Kataoka S and Kikuchi M: Safety evaluation of proanthocyanidin-rich extract from grape seeds. Food and Chemical Toxicology Journal,2002 May ;40 (5) :599-607.

- Yoshiyama M, Tay FR, Doi J, Nishitani Y, Yamada T, Itou K, Carvalho RM, Nakajima M and Pashley DH: Bonding of self-etch and total-etch adhesives to carious dentin. Journal of Dental Research, 2002 Aug;81(8):556-60. 